\title{
Focal Sheathing of Retinal Arteries in Tuberous Sclerosis
}

Sunil

Pradhan

Department of Neurology, Sanjay Gandhi Postgraduate Institute of Medical Sciences, Lucknow, India

\section{Sunil Pradhan, MD, DM, Department of Neurology, Sanjay Gandhi Post-Graduate, Institute of Medical Sciences PB 375, Lucknow 226001 (India)}

Dear Sir,

With this letter I would like to call to the attention of your readership neuro-ophthalmological findings that may appear early in the course of tuberous sclerosis and precede neurologic findings.

In tuberous sclerosis, the milder manifestations are common and some patients may never show the classical features of epilepsy, mental retardation and adenoma sebaceum [1]. The minor features, which include ophthalmic signs, are useful in the early diagnosis of these cases. In the absence of classical signs, complete ophthalmic examination is essential to screen a child in a family of tuberous sclerosis. Retinal or papillary phakomas of varying sizes are characteristic ocular lesions. A new ophthalmological finding of focal white sheathing of retinal arteries is being reported.

An asymptomatic boy of 4 years was screened for tuberous sclerosis. His mother had generalized tonic-clonic epilepsy since childhood. His only brother of 6 years of age started partial complex seizures at the age of 4 years and had mild mental retardation. Both mother and brother had adenoma sebaceum of the face and periventricular hyperdense lesions on the CT scan. The brother also had a shagreen patch over the face and trunk and a retinal phakoma near the left optic disc. Examination of the case revealed two ash leaf marks on the left thigh, small adenoma sebaceum over the face and a shagreen patch near the left angle of the mouth. No clinical evidence of mental retardation, visual disturbance or epileptic fits was observed in the case. His EEG was normal. The CT scan showed multiple small periventricular hyperdense lesions. Fundus examination (see fig. 1) revealed two small pale slightly raised phakomas in the left eye. These were situated about 1.5 disc diameters away from the disc on temporal side. There was a small pigmented spot along the inferotemporal blood vessels. Superior and inferior temporal branches of the retinal arteries in the left eye showed focal white sheathing in a pipe stem manner and this made the vessel opaque in that region. At one place the vascular sheathing appeared connected to the phakoma through a hazy background.

Tuberous sclerosis is a congenital and heredofamilial neurecto-dermal dysembryopathy. The classical lesions of tuberous sclerosis are hamartomas, the benign 'tumours' which may occur in brain, eyes, lungs and kidneys. The various pathognomonic signs are: adenoma sebaceum, hypomelanotic macules, subungual fibroma, multiple periventricular tubers, angiolipoma of kidney, pits of the teeth enamel and retinal phakomas. Ocular manifestations of tuberous

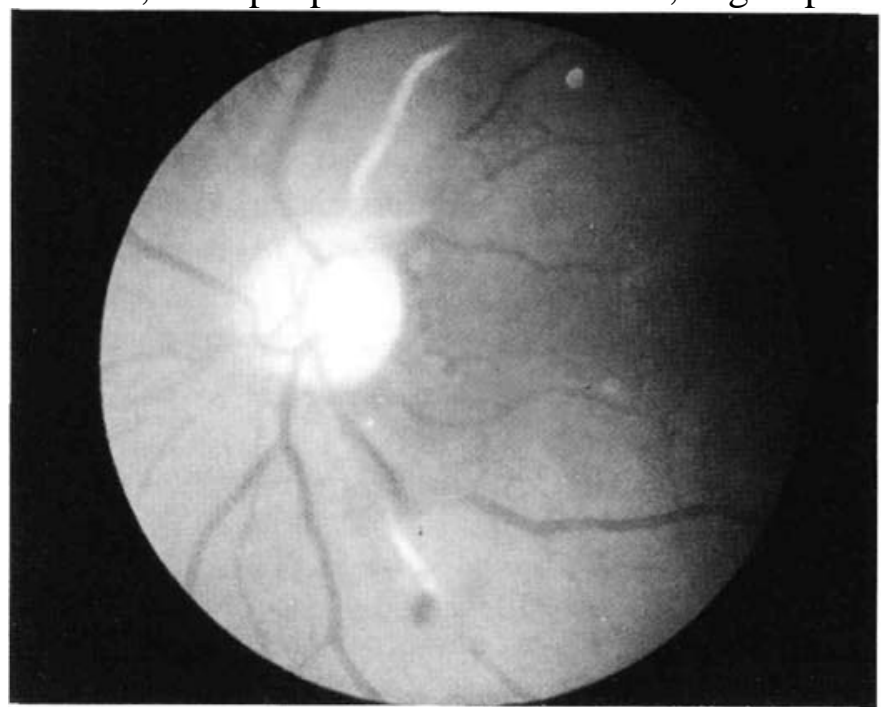

Fig. 1. Fundus photograph of the left eye. Note the localized white sheathing of superior and inferior temporal branches of the retinal artery.

sclerosis are more frequent than usually thought. Nearly half of the cases of tuberous sclerosis have ocular findings and retinal phakomas are seen in about 30 $50 \%$ of the cases. Other rarer ophthalmological signs include drusen of the optic disc, retinitis pigmentosa, choreoretinal depigmented and pigmented spots, atypical choreo-retinal coloboma, opacities of cornea and lens, papilloedema, primary and secondary optic atrophy and angiofibroma of the eyelid [2]. Apart from sheathing of the retinal arteries, the present case had 2 retinal phakomas and a small pigmented spot on fundus examination. The classical retinal lesions (phakomas and retinal spots) are benign proliferation of polymorphous astrocytic glial cells of embryonic origin. The phakomas are greyish-white tumours, raised from surface and often having an irregular surface and margins. The retinal spots are seen as round or oval plaques which are yellowish280

Pradhan

white or grey in colour, non-vascular, hardly raised and with hazy edges. They are single or more often multiple and have no relationship with vessels but may cover them if present at the same level [2]. These lesions do not produce symptoms unless they are located in papillomacular bundle. Nevertheless, they are worth looking for as they are pathognomonic of the disease. This patient had a rare retinal lesion showing pipe stem sheathing of the arteries. Anatomically, 
the retinal vessels are surrounded by a complicated system of neu-roglial sheath insulating the mesodermal vascular element from neural ectoderm. Since phakomas originate in the same nerve fibre layer of the retina in which retinal vessels are embedded [3], a selective glial proliferation along the vessel appears to be the most tenable explanation for vascular sheathing in the present case. Occasionally retinal blood vessels course through the tumor to manifest as sheathing adjacent to phakoma. In one exceptional case of tuberous sclerosis, 'white vessels' were found in association with retinal tumours [4]. In another case of tuberous sclerosis 'striped white veil' was found extending from the papilla covering the retinal vessels and resembling mylin fibres [5]. A somewhat similar finding was reported by Busch and Busch [6]. The present case differs from these reports in that the sheathing of vessels was focal and was not due to the retinal phakoma being situated in front of the vessels as is evident from the fact that the accompanying retinal vein is spared. As the ophthalmological signs may be the sole manifestations or may precede the neurologic and other systemic manifestations of tuberous sclerosis, these may contribute significantly to the early diagnosis of some cases and the present finding may be important in this regard.

References

Barakat AY, Cochran WE: Tuberous sclerosis. Clin Pediatr 1978;17:875-879.

Francois J: Ocular aspects of phakomatosis; in Vinken PJ, Bruyn GW (eds): Handbook of Clinical Neurology. Amsterdam, North Holland Publishing, 1972, vol 14: The Phakomatosis, pp 619-667.

Martin AJ: Tuberous sclerosis complex. Scott Med J 1968; 13: 295-296.

Tamura E, Suzuki M, Kamoshita S, Arima M, Fukuyama Y: Clinical observation of phakomatosis in infancy and childhood. II. Tuberous sclerosis. Paediatr Univ (Tokyo) 1964; 10:35-41.

Luo TH: Conjunctival lesions in tuberous sclerosis. Am J Oph-thalmol 194O;23:1029-1034.

Busch KT, Busch G: Neuro-ophthalmologische Befunde bei der tuberosen Sklerose (Morb. Bourneville). Klin Monatsbl Augen-heildk 1962;141 :388-4OI. 